\title{
Phosphorus ingestion improves oral glucose tolerance of healthy male subjects: a crossover experiment
}

\author{
May Khattab', Christelle Abi-Rashed ${ }^{1}$, Hala Ghattas ${ }^{1}$, Sani Hlais ${ }^{2}$ and Omar Obeid ${ }^{\text {* }}$
}

\begin{abstract}
Background: Fasting serum phosphorus $(P)$ was reported to be inversely related to serum glucose and insulin, while the impact of $P$ ingestion is not well documented. The effect of $P$ intake with or before glucose ingestion on postprandial glucose and insulin statuses was investigated.

Method: Two cross over experiments using healthy male subjects were conducted. Experiment 1: Overnight fasted subjects $(n=7)$ randomly received: $500 \mathrm{mg}$ of $\mathrm{P}$ tablets, glucose $(75 \mathrm{~g})$ solution with placebo or $500 \mathrm{mg}$ of $\mathrm{P}$ tablets. Experiment 2: Overnight fasted subjects $(n=8)$ underwent similar procedures to those of experiment 1 , except that placebo or $500 \mathrm{mg} P$ tablets were given 60 min prior to glucose ingestion.

Results: In both experiments, serum $\mathrm{P}$ decreased following glucose ingestion. Co-ingestion of $\mathrm{P}$ with glucose improved, at time 60 min, postprandial glucose $(P<0.05)$, insulin $(P<0.05)$, and insulin sensitivity index $(p<0.006)$, while $P$ pre-ingestion failed to exert similar effect.

Conclusion: This study suggests that postprandial glucose and insulin are affected by exogenous P supply, especially when co-ingested with glucose.
\end{abstract}

Keywords: Phosphorus, Glucose, Area under the curve, OGTT, Insulin sensitivity

\section{Introduction}

Over the past few decades, the high prevalence of metabolic syndrome has become a worldwide phenomenon, associated with an increased risk and prevalence of type 2 diabetes mellitus [1]. This increasing phenomenon has been found to be associated with dietary and lifestyle changes, which favor the consumption of phosphorus (P)-deficient food items [2]. In parallel, plasma phosphate levels were found to be synergistically related to glucose tolerance and insulin sensitivity [3-5]. The association between $\mathrm{P}$ and glucose is believed to be mediated by insulin [6], as a result of its capacity to stimulate both $P$ uptake by the muscles [7] and phosphorylation of many compounds; thereby, creating a competition [8] among these compounds for $\mathrm{P}$.

\footnotetext{
*Correspondence: 0001@aub.edu.lb

'Department of Nutrition and Food Sciences, American University of Beirut, Beirut, Lebanon

Full list of author information is available at the end of the article
}

Additionally, overweight and/or obesity, a known risk factor for type 2 diabetes mellitus, is reported to be inversely related to plasma $\mathrm{P}[2,3]$. The intakes of high protein food choices, which are rich sources of $\mathrm{P}$, have been reported to improve weight loss [9] by a calcium independent mechanism $[10,11]$. Furthermore, the intake of dairy products has been also found to be associated with a lower risk for type 2 diabetes mellitus in three meta-analyses of large prospective epidemiological studies [12-15]. Moreover, since post-prandial glycaemia is a risk factor for type 2 diabetes mellitus [16, 17], it is reasonable to postulate that $\mathrm{P}$ is involved in its development. Several dietary, lifestyle and pharmaceutical approaches have been used to reduce postprandial glycaemia, including the enhancement of intracellular glucose trapping. Recently glucokinase activators have been developed and tested, but their capacity to improve glycaemia was associated with several side effects [18-20] that may be attributed to hepatic intracellular P depletion, especially since a limited quantity of free $\mathrm{P}$ is present intracellularly. 
In brief, increased incidence of glucose intolerance and type 2 diabetes mellitus is associated with dietary changes that favor a reduction in the consumption of $\mathrm{P}$, an important mediator in glucose metabolism [5, 2123]. Despite the presence of evidence showing the inefficiency of fasting P to reflect its diurnal [24] or postprandial status [25], a positive association between fasting $\mathrm{P}$ levels and insulin sensitivity has been reported [26].

Micronutrients enrichment of carbohydrate meals was reported to reduce post-prandial glycaemia [27]. Although $\mathrm{P}$ is tightly integrated in the metabolism of glucose, the impact of $\mathrm{P}$ ingestion on glucose tolerance and insulin resistance of healthy subjects is not well documented. However, phosphate infusion of healthy subjects was reported to improve insulin sensitivity under euglycaemic conditions [6] and phosphate supplementation of hypophosphatemic glucose intolerant patients improved glucose tolerance [28]. The aim of this study was to investigate the effect of exogenous $\mathrm{P}$ on postprandial glucose and insulin status in healthy subjects. Based on that, this study holds significance in the advances of human nutrition in improving glucose tolerance and therefore preventing the development of type 2 diabetes mellitus in humans.

\section{Subjects and methods}

The study was comprised of two experiments. Healthy male subjects were recruited to perform the experiments (Table 1). Placebo (cellulose) or P (125 mg of potassium phosphate per tablet) tablets, which had similar weight and color, were administered to subjects in a randomized order to prevent order-of-treatment effect. The study protocol was approved by the Institutional Review

Table 1 Characteristics of the study subjects

\begin{tabular}{lr}
\hline Characteristics & Mean \pm SEM \\
\hline Experiment $1(n=7)$ & \\
Age (years) & $23.22 \pm 1.83$ \\
Weight $(\mathrm{kg})$ & $68.88 \pm 4.05$ \\
Height $(\mathrm{m})$ & $1.74 \pm 0.02$ \\
BMl $\left(\mathrm{kg} / \mathrm{m}^{2}\right)$ & $22.65 \pm 0.82$ \\
Fasting glucose $(\mathrm{mg} / \mathrm{dl})$ & $86.38 \pm 1.62$ \\
Fasting triglycerides $(\mathrm{mg} / \mathrm{dl})$ & $90.63 \pm 15.9$ \\
Fasting phosphorus $(\mathrm{mg} / \mathrm{dl})$ & $4.06 \pm 0.19$ \\
Experiment 2 $(n=8)$ & \\
Age $(y e a r s)$ & $27.3 \pm 1.68$ \\
Weight $(\mathrm{kg})$ & $73 \pm 4.78$ \\
Height $(\mathrm{m})$ & $1.76 \pm 0.04$ \\
BMl $\left(\mathrm{kg} / \mathrm{m}^{2}\right)$ & $23.5 \pm 0.97$ \\
Fasting glucose $(\mathrm{mg} / \mathrm{dl})$ & $88 \pm 2.17$ \\
Fasting triglycerides $(\mathrm{mg} / \mathrm{dl})$ & $119 \pm 15.3$ \\
Fasting phosphorus $(\mathrm{mg} / \mathrm{dl})$ & $3.75 \pm 0.2$ \\
\hline
\end{tabular}

Board committee at the American University of Beirut, in addition to consent forms that have been obtained from patients.

\section{Experiment 1: the effect of phosphorus ingestion on oral glucose tolerance test [OGTT]}

Seven overnight fasted subjects (age (mean \pm SEM): $23.2 \pm$ 1.83 years; BMI: $22.65 \pm 0.82 \mathrm{~kg} / \mathrm{m}^{2}$ ) (Table 1: Experiment 1 ) were asked to attend 3 experimental sessions that were separated by a minimum of 3 days. Sessions included the consumption of either $500 \mathrm{mg}$ of P (4 tablets), a glucose solution ( 75 g glucose) with 4 Placebo tablets, or a glucose solution (75 g glucose) with $500 \mathrm{mg}$ P. All were ingested with $250 \mathrm{ml}$ of cold water. Blood was withdrawn at baseline and monitored till $240 \mathrm{~min}(\mathrm{~min})$ after consumption.

\section{Experiment 2: the effect of pre-phosphorus ingestion on OGTT}

Based on data from experiment 1, peak serum P concentration $(60 \mathrm{~min})$ was associated with significant decrease in serum glucose and insulin levels. Thus, experiment 2 was designed to investigate whether $\mathrm{P}$ intake one hour prior to glucose ingestion would potentiate the effect of $\mathrm{P}$ on postprandial glucose and insulin levels. Eight overnight fasted subjects (age: $27.3 \pm 1.68$ years; BMI: $23.5 \pm$ $0.97 \mathrm{~kg} / \mathrm{m}^{2}$ ) (Table 1: Experiment 2) attended 2 experimental sessions that were separated by a minimum of 3 days. Subjects were given placebo or P $(500 \mathrm{mg})$ tablets $60 \mathrm{~min}$ prior to glucose ingestion. Blood was drawn at baseline $(-60 \mathrm{~min})$ and monitored till $240 \mathrm{~min}$ relative to glucose ingestion.

\section{Laboratory analyses}

Serum was separated from collected blood samples and stored at $-80{ }^{\circ} \mathrm{C}$ for later analysis of glucose, total $\mathrm{P}$, triglyceride and insulin. Glucose was measured from venous samples. Insulin sensitivity was estimated by the method of Caumo et al. [29] and expressed as ( $x$ $\left.10^{4} \mathrm{dl} . \mathrm{kg}^{-1} \cdot \mathrm{min}^{-1} \cdot \mu \mathrm{Uml}^{-1}\right)$. The method is based on the kinetic of both glucose and insulin through coupling their rate of appearance into circulation following oral glucose ingestion. It is based on simple area under the curve type of calculation and was validated in normal subjects in whom their calculated insulin sensitivity was strongly correlated to that of frequentl formula y sampled iv glucose test (FSIGT) [29]. In addition, index of insulin sensitivity was calculated using the composite equation proposed by Matsuda and DeFronzo [30].

\section{Statistical analyses}

Data are presented as means \pm SEM. Paired t-tests were used to compare between treatments and to detect the difference from baseline within each treatment. Repeated Measure ANOVA was run to test the effect of treatment 
groups over time on each of the dependent variables ( $P$, Glucose and insulin). The level of significance was fixed at $P<0.05$.

\section{Results}

Baseline serum levels of the different parameters (total P, glucose, insulin) were similar between sessions and both experiments (Table 1).

\section{Experiment 1}

Ingestion of $\mathrm{P}$ alone increased serum $\mathrm{P}$ significantly, while ingestion of glucose alone decreased postprandial serum $\mathrm{P}$ levels. The pattern of serum $\mathrm{P}$ changes following glucose and $P$ ingestion $(G+P)$ was different than that of the other two treatments (Fig. 1a), in line, repeated measures ANOVA showed that serum P was significant according to treatment (Table 2: Experiment 1).
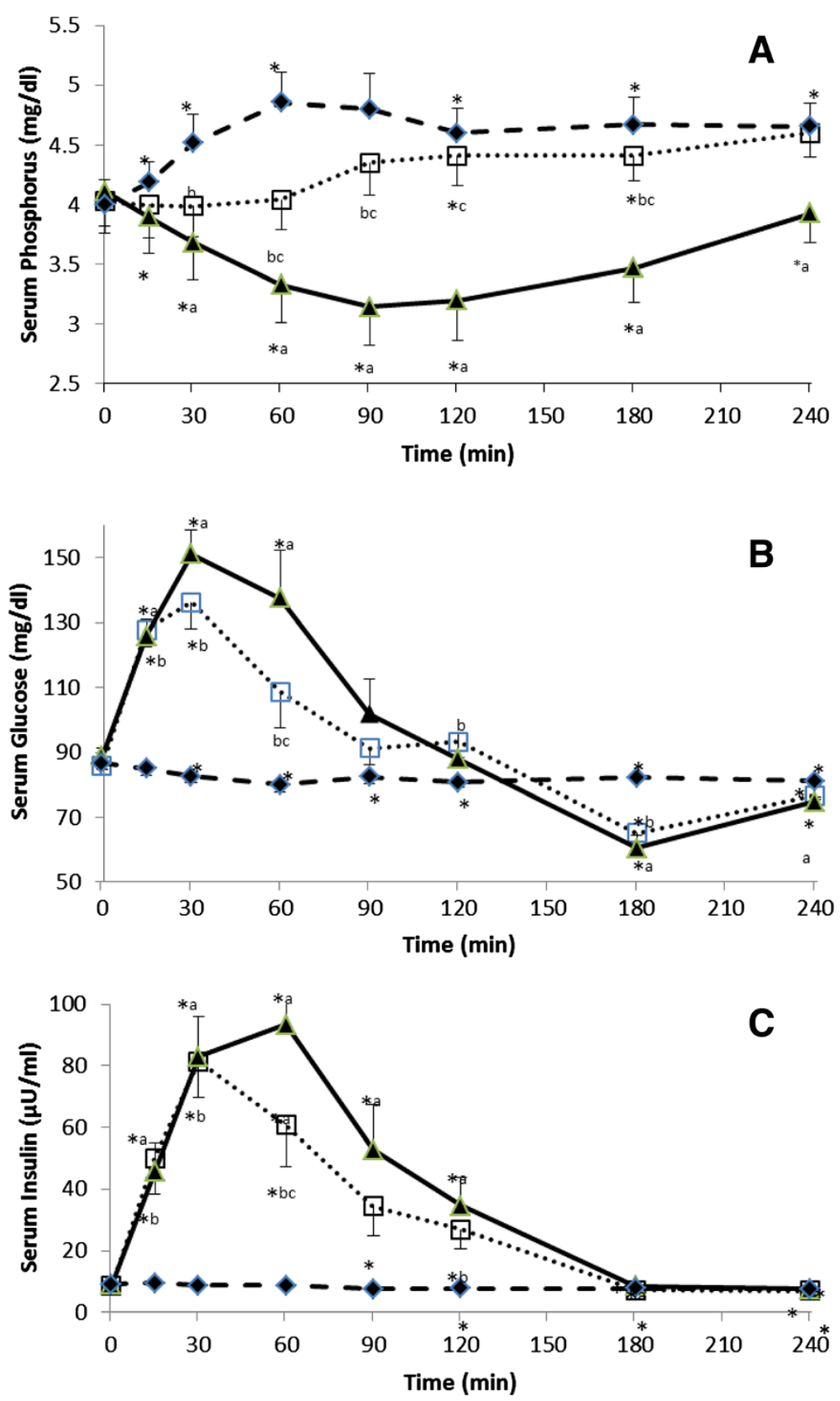

Fig. 1 Changes in Serum Phosphorus (a), Glucose (b) and Insulin (c) levels of subjects in experiment1. \#Experiment 1: After the ingestion of $500 \mathrm{mg}$ phosphorus (- - ), $75 \mathrm{~g}$ glucose $\left(-\boldsymbol{\Delta}\right.$-) or co-ingestion glucose + phosphorus (75 g glucose $+500 \mathrm{mg}$ of phosphorus) $(. . \square ..) .{ }^{*} p$-value $<0.05$ : Paired t-test in the same treatment in comparison with baseline (time 0 ) value. ${ }^{a} p$-value $<0.05$ : Paired t-Test, phosphorus vs glucose treatments at each time point. ${ }^{b} p$-value $<0.05$ : Paired t-Test, phosphorus vs glucose + phosphorus treatments at each time point. ${ }^{c} p$-value $<0.05$ : Paired t-Test, glucose vs glucose + phosphorus treatments at each time point 
Table 2 Repeated measure ANOVA outcome variables (Phosphorus, glucose and Insulin) of the two experiments

\begin{tabular}{llll}
\hline $\begin{array}{l}\text { Outcome variables } \\
\text { Experiment } 1(n=7)^{\mathrm{a}}\end{array}$ & $\begin{array}{l}\text { Time } \\
(P \text { value })\end{array}$ & $\begin{array}{l}\text { Treatment } \\
(P \text { value })\end{array}$ & $\begin{array}{l}\text { Interaction } \\
(P \text { value })\end{array}$ \\
\hline Serum Phosphorus & 0.616 & 0.000 & 0.321 \\
Serum Glucose & 0.000 & 0.145 & 0.207 \\
$\quad$ Serum Insulin & 0.000 & 0.168 & 0.619 \\
Experiment 2 $(n=8)$ & & & \\
$\quad$ Serum Phosphorus & 0.001 & 0.002 & 0.498 \\
Serum Glucose & 0.000 & 0.815 & 0.961 \\
Serum Insulin & 0.000 & 0.233 & 0.724 \\
\hline
\end{tabular}

a Only glucose with placebo and glucose with P groups were included in the analysis

Postprandial serum glucose concentration of the P treatment group significantly decreased by around $5 \mathrm{mg} / \mathrm{dl}$ during the experimental session, but this minimal reduction is believed to be the result of fasting. Glucose ingestion increased postprandial serum glucose levels of both treatments, glucose and $G+P$, but the magnitude of the increase was significantly lower in the $G+P$ as compared to glucose treatment at time $60 \mathrm{~min}(P=0.016)$, (Fig. 1b). Repeated measures ANOVA showed that serum glucose levels were significantly different according to time, but failed to reach statistical significance between treatments (Table 2: Experiment 1).

Ingestion of $\mathrm{P}$ alone did not alter postprandial insulin concentration. Insulin levels of the $\mathrm{G}+\mathrm{P}$ treatment were significantly lower $(P=0.002)$ than that of the glucose treatment at time $60 \mathrm{~min}$ (Fig. 1c). Repeated measures ANOVA found that serum insulin was significant according to time only (Table 2: Experiment 1). Insulin sensitivity obtained from oral glucose tolerance test and according to Caumo et al. [29] formula increased following $\mathrm{G}+\mathrm{P}$ treatment and the difference was close to significance $(P=0.051)$ (Table 3 : Experiment 1$)$. While index of insulin sensitivity increased significantly $(P=$ 0.006) following the addition of P to OGTT (Table 3: Experiment 1). Insulin sensitivity of the $\mathrm{P}$ ingestion

Table 3 Measures of insulin sensitivity from oral glucose tolerance test

\begin{tabular}{lrrl}
\hline Outcome variables & Placebo & Phosphorus & $\begin{array}{l}\text { Paired t-test } \\
(P \text { value })\end{array}$ \\
\hline Experiment 1 $(n=7)$ & & & \\
$\quad$ Insulin sensitivity index [30] & $5.69 \pm 0.86$ & $7.00 \pm 1.06$ & 0.006 \\
$\quad$ Insulin sensitivity [29] & $12.19 \pm 3.85$ & $20.22 \pm 6.65$ & 0.051 \\
Experiment 2 $(n=8)$ & & & \\
$\quad$ Insulin sensitivity index [30] & $9.17 \pm 0.97$ & $8.88 \pm 0.78$ & 0.633 \\
$\quad$ Insulin sensitivity [29] & $15.31 \pm 2.58$ & $18.39 \pm 3.28$ & 0.210 \\
\hline
\end{tabular}

treatment was not determined since postprandial glucose and insulin levels were minimally affected.

\section{Experiment 2}

Ingestion of placebo tablets had no effect on serum $\mathrm{P}$ levels prior to glucose ingestion, but glucose ingestion decreased serum P levels (Fig. 2a). Following P ingestion, serum $\mathrm{P}$ levels increased significantly at time 0 and $15 \mathrm{~min}$ and then returned to baseline levels (Fig. 2a). Repeated measures ANOVA analysis of all time points showed that serum $\mathrm{P}$ was significant according to time and treatment (Table 2: Experiment 2). Serum glucose levels of the glucose and G + P treatments increased significantly following glucose ingestion (Fig. 2b). The increase in glucose levels was similar between the two treatments, except for a slight difference at time baseline and $240 \mathrm{~min}$ believed to be of no clinical significance (Fig. 2b). In line, repeated measures ANOVA were significant according to time only (Table 2: Experiment 2).

Glucose ingestion increased insulin levels of both treatments, but the magnitude of this increase was modestly lower in the P preload treated group (Fig. 2c) and repeated measures ANOVA failed to detect difference according to treatment (Table 2: Experiment 2). Measures of insulin sensitivity were found to be similar between the two treatments and this was expected since the changes in insulin and glucose were similar between the treatments (Table 2: Experiment 2).

\section{Discussion}

In agreement with other studies, ingestion of $\mathrm{P}$ alone (experiment 1 and 2) increased postprandial serum $\mathrm{P}$ [31], while ingestion of grape juice [31], glucose alone [32-34], or other type of carbohydrate [35] reduced postprandial serum P levels. Glucose may indirectly affect $\mathrm{P}$ status through the stimulation of peripheral $\mathrm{P}$ uptake by insulin [7, 36, 37], which in turn stimulates the phosphorylation of several compounds including carbohydrate [35], fat and protein. About $60 \%$ of infused $\mathrm{P}$ has been reported to be translocated from the extracellular to the intracellular compartment [6], mainly in skeletal muscles [21, 36]. This translocation is believed to be mediated via insulin action as glucose infusion in pancreatectomic dogs failed to induce a reduction in serum $P$ except when insulin became available [21, 37, 38]. In line with this, the parallel increase in postprandial glucose and insulin (peaks at 30-60 min) was followed by a decrease in serum P (dip at $90 \mathrm{~min}$ ). Therefore, under conditions of P intake alone, intracellular P is likely to have been affected since insulin was not altered.

In the current study, both co- and pre-ingestion of $\mathrm{P}$ were able to halt the drop in serum $\mathrm{P}$ levels following glucose ingestion. In the $G+P$ treatment, increased $P$ 

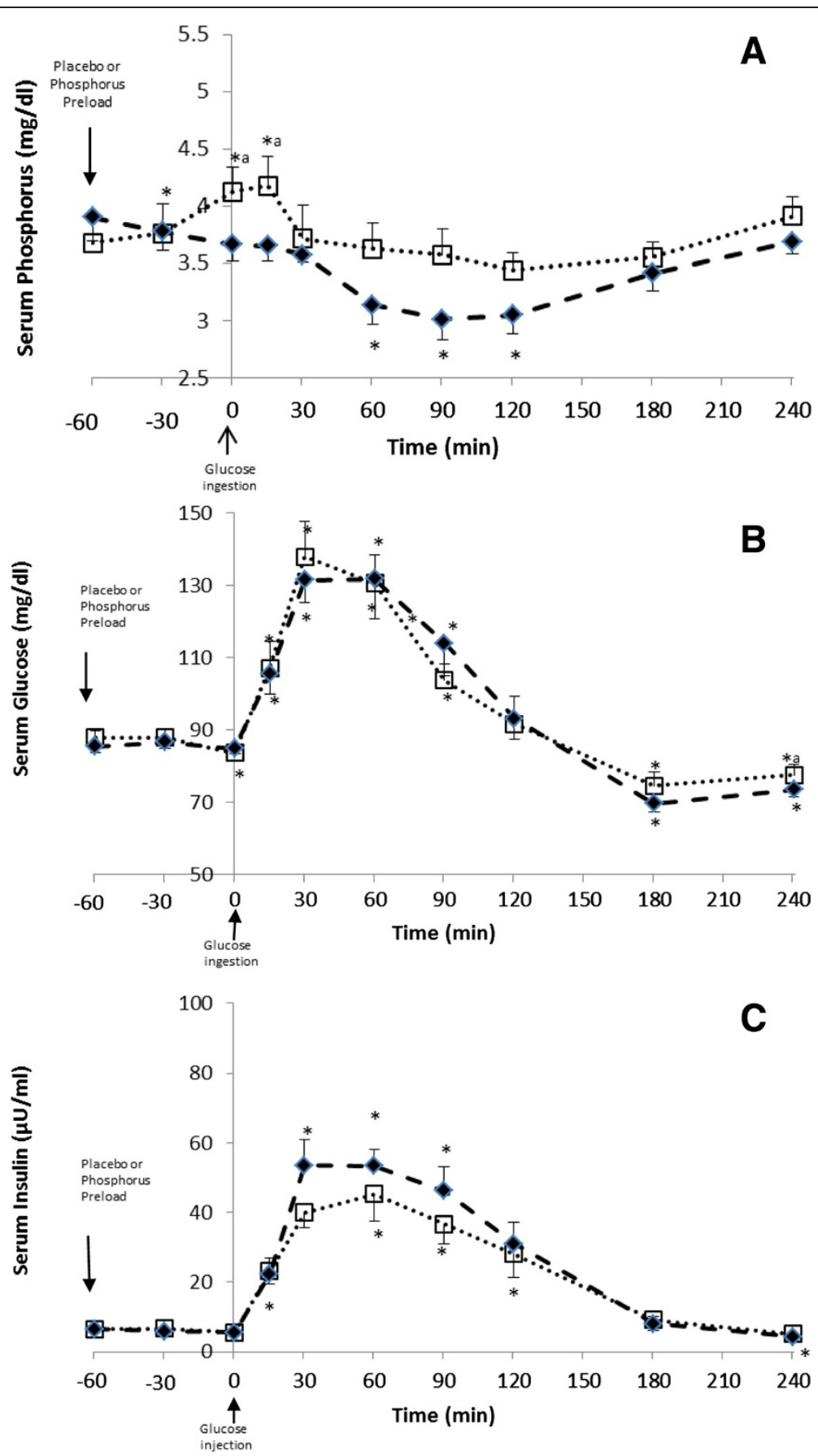

Fig. 2 Changes in Serum Phosphorus (a), Glucose (b), and Insulin (c) levels of subjects in experiment2. \#Experiment 2: After the he ingestion of $75 \mathrm{~g}$ glucose $60 \mathrm{~min}$ after placebo $(-)$ or $500 \mathrm{mg}$ phosphors (....) preload. * $p$-value $<0.05$ : Paired t-test in the same treatment in comparison with baseline (time $-60 \mathrm{~min}$ ) value. ${ }^{a} p$-value < 0.05: Paired t-Test between placebo and phosphorus preload treatments at each time point

uptake and availability might have contributed to the drop in glucose and insulin levels at time $60 \mathrm{~min}$, due to an increase in intracellular glucose trapping (phosphorylation), especially since insulin release depends on glucose circulation. This process might have played a role in the observed improvement in the measures of insulin sensitivity following P ingestion with glucose (Experiment 1). Phosphorylation or
$\mathrm{P}$ trapping seems to have been substantially stimulated or became dependent on extracellular P $30 \mathrm{~min}$ after glucose ingestion; as indicated by the drop in postprandial serum $\mathrm{P}$ levels. This may partially be behind the failure of $\mathrm{P}$ preingestion to impact postprandial plasma glucose, since the majority of phosphorus is known to be absorbed within $60 \mathrm{~min}$, as supported by the finding from experiment 1 . 
When glucose was ingested alone, the low availability of $\mathrm{P}$ may have hindered insulin phosphorylation capacity through creating competition for P. Such competition may have deleterious effects since it can affect glucose clearance and trapping, glycolysis and gluconeogenesis [39], and phospholipids and hepatic fat accumulation [40]. Therefore, postprandial glycemia and insulinemia seem to be improved by exogenous $\mathrm{P}$ availability and this may partially explain the reported association between low serum $\mathrm{P}$ with insulin resistance and elevated blood glucose levels $[5,23]$.

Ingestion of $\mathrm{P}$ before or with glucose was able to prevent the drop in postprandial serum $P$ levels. The sustained high postprandial serum $P$ in the $G+P$ treatment in comparison to that of the glucose ingestion alone implies that intracellular P uptake may be controlled by a limited capacity for phosphorylation and/ or glucose uptake. In healthy subjects, peripheral glucose uptake, especially in skeletal muscles, is known to be triggered by insulin dependent Glut 4 stimulation [41]. While, intracellular glucose phosphorylation is controlled by the activities of glucokinase (liver) and hexokinase (muscle), the latter has a low Vmax (maximum velocity) capacity and is highly inhibited by glucose-P production [42]. The reduction in serum glucose of the $\mathrm{G}+\mathrm{P}$ treatment argues against a defect in Glut 4 (glucose uptake), therefore the sustenance in plasma $\mathrm{P}$ may have been attributed to the low Vmax capacity of muscle hexokinase. Accordingly, ingestion of higher $\mathrm{P}$ doses would not be expected to further improve glucose, insulin, or insulin sensitivity.

The fact that $\mathrm{P}$ is absorbed along the entire intestinal tract $[22,43]$ could be responsible for the observed high plasma P levels (above baseline value) in the G + P treatment beyond the time $(120 \mathrm{~min})$ of availability of glucose and insulin. Moreover, the difference in the magnitude of changes in postprandial glucose and insulin levels between the preload and the co-ingestion experiments implies that factors beyond the availability of circulating P, glucose and insulin may have been involved in improving of insulin sensitivity. The weak significant association seen between $\mathrm{P}$ preload on insulin sensitivity could be explained by the small sample size of the present study. On the other hand, glucosephosphorus interaction in the proximal part of the small intestine may been involved in insulin sensitivity through incretin hormones. These hormones, especially glucagon like peptide-1 (GLP-1) and gastric inhibitory polypeptide (GIP) are known to be secreted in response to meal ingestion, especially high protein meals (rich in P) $[9,42]$ and were reported to affect insulin status and to play an important role in regulating postprandial blood glucose $[9,44,45]$.

The observed improvement in the measures of insulin sensitivity following meal-phosphorus co-ingestion may have been partially involved in the reported synergic relationship between the intake of whole grains and glucose tolerance [46]. Especially since this relationship was not explained by the function of dietary fiber [47] and whole grains are rich in phosphors. Additionally, our observation may partially explain the observed parallel rise in metabolic syndrome with global urbanization and westernization of dietary habits, which favor low $\mathrm{P}$ intake [3]. In comparison to other studies in the literature, which have used $P$ injections to study its effect on glycaemia and insulinemia [6], the current study used a different method that mimicked daily dietary habits, through the ingestion of $500 \mathrm{mg}$ of $\mathrm{P}$ with a glucose load (approximately $1.7 \mathrm{mg}$ of $\mathrm{P}$ per $\mathrm{Kcal}$ ). Therefore, these findings highlight the role of $\mathrm{P}$ in improving the states of hyperglycemia and hyperinsulinemia in healthy individuals without the influence of serum calcium and FGF-23 which did not vary when $P$ is used [25].

On the other hand, elevated fasting serum $P$ levels were reported to be associated with mortality among patients with chronic kidney [48] and coronary [49] diseases. The association was partially explained by the capacity of high $\mathrm{P}$ conditions to induce vascular calcification and endothelial injury using in vitro studies [50-53]. Moreover, in a human (in vivo) study endothelial function impairment was apparent under high (1200 mg P/meal) and not normal (400 mg P/meal) P ingestion [54]. In fact, the negligible impact of dietary $\mathrm{P}$ intake on serum $\mathrm{P}$ levels implies that factors associated with increased serum $\mathrm{P}$, rather than $\mathrm{P}$ intake, were probably behind the association between cardiovascular disease and serum $P$ [24]. Recently, a weak association between dietary P intake and all-cause mortality was reported [55] and this was questioned since participants adopted different dietary patterns and $\mathrm{P}$ intake was not the only variable. Thus, the nature of the relation between $\mathrm{P}$ intake and cardiovascular disease and mortality is far from clear and requires further scrutiny [56].

In the present study, sample size was based on the previously reported data of AUC for glucose [57]. However, the observed large variations between subjects seem to have diluted the impact of the interventions. Further studies, using a larger sample size, would help in exploring the mechanisms by which the observed effects are mediated especially by examining the role of incretin hormones.

The limitation of this study lies in its small number of subjects enrolled into the experimental design. Moreover, although the dietary habits of these subjects were not assessed prior to the initiation of the study; however, as stated previously, fasting serum P status is not a good indicator of $\mathrm{P}$ intake. Postprandial status of the measured parameters is not likely to be affected by prior meal intake since all subjects were overnight fasted. Therefore, assessing dietary habits of subjects has no added implications on the study results. 


\section{Conclusion}

Ingestion of $\mathrm{P}$ with glucose was found to reduce postprandial glucose and insulin levels mainly at time $60 \mathrm{~min}$. This was associated with a significant reduction in insulin sensitivity index. These changes are likely to have been attributed to phosphorus capacity to enhance insulin mediated peripheral phosphorylation, which is highly dependent on extracellular phosphorus availability or exogenous (dietary) phosphorus supply. Dietary phosphorus intake can exert its beneficial impact and prevent the deleterious effect of depleting intracellular phosphorus.

\section{Abbreviations}

P: Phosphorus; G: Glucose; G + P: Ingestion of glucose and phosphorus; AUC: Area under the curve.

\section{Competing interests}

The authors declare that they have no competing interests.

\section{Authors' contributions}

MK carried out the studies, sample analysis and writing of manuscript. CAR carried out the studies, sample analysis and writing of manuscript. GH contributed to data analysis and writing of the manuscript. SH performed the statistical analysis. 00 made substantial contributions to conception, design, acquisition of data, analysis, and interpretation of data. All authors read and approved the final manuscript.

\section{Acknowledgements}

The research was supported by Lebanese National Council for Scientific Research (LNCSR) and University Research Board (URB). The following sponsors did not participate in the design or conduct of this study, collection, management, analysis, or interpretation of the data, writing of the manuscript, or in the preparation, review, approval or decision to submit this manuscript for publication.

We thank Dr Mazen Al-Ghoul for his mathematical support for the calculation of insulin sensitivity.

\section{Author details}

${ }^{1}$ Department of Nutrition and Food Sciences, American University of Beirut, Beirut, Lebanon. ${ }^{2}$ Department of Family Medicine, American University of Beirut, Beirut, Lebanon.

\section{Received: 6 May 2015 Accepted: 12 October 2015}

\section{Published online: 29 October 2015}

\section{References}

1. Grundy SM. Metabolic syndrome pandemic. Arterioscler Thromb Vasc Biol. 2008;28:629-36.

2. Obeid O. Low phosphorus status might contribute to the onset of obesity. Obes Rev. 2013;14:659-64.

3. Haap M, Heller E, Thamer C, Tschritter O, Stefan N, Frittsche A. Association of serum phosphate levels with glucose tolerance, insulin sensitivity and insulin secretion in non-diabetic subjects. Eur J Clin Nutr. 2006;60:734-9.

4. DeFronzo RA, Lang R. Hypophosphatemia and glucose intolerance: evidence for tissue insensitivity to insulin. N Engl J Med. 1980;303:1259-63.

5. Park W, Kim BS, Lee JE, Huh JK, Kim BJ, Sung KC, et al. Serum phosphate levels and the risk of cardiovascular disease and metabolic syndrome: a double-edged sword. Diabetes Res Clin Pract. 2009;83:119-25.

6. Nowicki M, Fliser D, Fode P, Ritz E. Changes in plasma phosphate levels influence insulin sensitivity under euglycemic conditions. J Clin Endocrinol Metab. 1996;81:156-9.

7. Venkataraman P, Blick K, Rao R, Fry H, Parker M. Decline in serum calcium, magnesium and phosphorus values with oral glucose in normal neonates: studies of serum parathyroid homone and calcitonin. J Pediatr. 1986;108:607-10.
8. Oberhaensli RD, Galloway GJ, Taylor DJ, Bore PJ, Radda GK. Assessment of human liver metabolism by phosphorus-31-magnetic resonance spectroscopy. Br J Radiol. 1986;59:695-9.

9. Veldhorst M, Smeets A, Soenen S, et al. Protein-induced satiety: effects and mechanisms of different proteins. Physiol Behav. 2008;94:300-7.

10. Yanovski JA, Parikh SJ, Yanoff LB, Denkinger BI, Calis KA, Reynolds JC, et al. Effects of calcium supplementation on body weight and adiposity in overweight and obese adults: a randomized trial. Ann Intern Med. 2009;150:821-9. W145-6.

11. Wagner G, Kindrick S, Hertzler S, DiSilvestro RA. Effects of various forms of calcium on body weight and bone turnover markers in women participating in a weight loss program. J Am Coll Nutr. 2007;26:456-61.

12. O'Connor LM, Lentjes MA, Luben RN, Khaw KT, Wareham NJ, Forouhi NG. Dietary dairy product intake and incident type 2 diabetes: a prospective study using dietary data from a 7-day food diary. Diabetologia. 2014 May;57(5):909-17.

13. Tong X, Dong JY, Wu ZW, Li W, Qin LQ. Dairy consumption and risk of type 2 diabetes mellitus: a meta-analysis of cohort studies. Eur J Clin Nutr. 2011;65:1027-31.

14. Elwood PC, Pickering JE, Givens DI, Gallacher JE. The consumption of milk and dairy foods and the incidence of vascular disease and diabetes: an overview of the evidence. Lipids. 2010;45:925-39.

15. Aune D, Norat $T$, Romundstad P, Vatten LJ. Dairy products and the risk of type 2 diabetes: a systematic reviewand dose-response meta-analysis of cohort studies. Am J Clin Nutr. 2013;98:1066-83.

16. Blaak EE, Antoine JM, Benton D, Björck I, Bozzetto L, Brouns F, et al. Impact of postprandial glycaemia on health and prevention of disease. Obes Rev. 2012;13:923-84

17. Gerich JE. Clinical significance, pathogenesis, and management of postprandial hyperglycemia. Arch Intern Med. 2003;163:1306-16.

18. De Ceuninck F, Kargar C, llic C, Caliez A, Rolin JO, Umbdenstock T, et al. Small molecule glucokinase activators disturb lipid homeostasis and induce fatty liver in rodents: a warning for therapeutic applications in humans. $\mathrm{Br} J$ Pharmacol. 2013;168:339-53.

19. Nissim I, Horyn O, Nissim I, Daikhin Y, Wehrli SL, Yudkoff M, et al. Effects of a glucokinase activator on hepatic intermediary metabolism: study with 13C-isotopomer-based metabolomics. Biochem J. 2012;444:537-51.

20. Meininger GE, Scott R, Alba M, Shentu Y, Luo E, Amin H, et al. Effects of MK0941, a novel glucokinase activator, on glycemic control in insulin-treated patients with type 2 diabetes. Diabetes Care. 2011;34:2560-6.

21. Harrop GA, Benedict EM. The participation of inorganic substances in carbohydrate metabolism. J Biol Chem. 1924;59:683-97.

22. Gropper SS, Smith JL. In: William P, editor. Advanced nutrition and human metabolism. 6th ed. Balmont: CA. Press; 2012. p. 20-6.

23. Harter H, Santiago J, Rutherford W, Slatopolsky E, Klahr S. The relative roles of calcium, phosphorus, and parathyroid hormone in glucose and tobultamide-mediated insulin release. J Clin Invest. 1976;58:359-67.

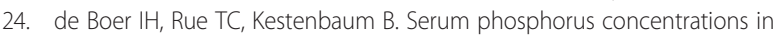
the third National Health and Nutrition Examination Survey [NHANES III]. Am J Kidney Dis. 2009;53:399-407.

25. Nishida $Y$, Taketani $Y$, Yamanaka-Okumura H, Imamura F, Taniguchi A, Sato $T$, et al. Acute effect of oral phosphate loading on serum fibroblast growth factor 23 levels in healthy men. Kidney Int. 2006;70:2141-7.

26. Obeid OA, Hachem DH, Ayoub JJ. Refeeding and metabolic syndromes: two sides of the same coin. Nutr Diabetes. 2014:4:e120. doi:10.1038/ nutd.2014.21.

27. Su-Que L, Meng Y-N, Li X-P, Zhang Y-L, Song G-Y, Ma H-J. Effect of consumption of micronutrient enriched wheat steamed bread on postprandial plasma glucose in healthy and type 2 diabetic subjects. Nutr J. 2013;12:64-7.

28. Wittmann I, Nagy N. Effectiveness of phosphate supplementation in glucose intolerant, hypophosphatemic patients. Miner Electrolyte Metab. 1997;23:62.

29. Caumo A, Bergman RN, Cobelli C. Insulin sensitivity from meal tolerance tests in normal subjects: a minimal model index. J Clin Endocrinol Metab. 2000;85:4396-402

30. Matsuda M, DeFronzo RA. Insulin sensitivity indices obtained from oral glucose tolerance testing: comparison with the euglycemic insulin clamp. Diabetes Care. 1999;22(9):1462-70.

31. Calvo MS, Heath $\mathrm{H}$. Acute effects of oral phosphate-salt ingestion on serum phosphorus, serum ionized calcium, and parathyroid hormone in young adults. Am J Clin Nutr. 1988;47:1025-9. 
32. Campillo JE, Aguayo J, Castillo M, Osorio C. Inorganic phosphate-insulin relationships in normal subjects and in patients with moderate glucose intolerance. Diabetes Metab. 1982;8:289-93.

33. Pollack H, Millet RF, Essex HE, Mann FC, Bollman JL. Serum phosphate changes induced by injections of glucose into dogs under various conditions. Am J Physiol. 1934;110:117-22.

34. Paula F, Plens E, Foss MC. Effects of hypophosphatemia on glucose tolerance and insulin secretion. Horm Metab Res. 1998;30:281-4.

35. Trautvetter U, Kiehntopf M, Jahreis G. Postprandial effects of calcium phosphate supplementation on plasma concentration-double-blind placebo-controlled cross-over human study. Nutr J. 2013;12:30-6.

36. Berthelay S, Saint-Hiller Y, Nguyen N, Henreit M, Dumoulin G, Wolf J, et al. Relations between oral glucose load and urinary elimination of calcium and phosphorus in healthy men with normal body weight. Nephrologie. 1984:5:205-7.

37. Briggs A, Koechig I, Doisy E, Weber C. Some changes in the composition of blood due to the injection of insulin. J Biol Chem. 1924;58:721-30.

38. Markowitz J. The relationship of phosphate and carbohydrate metabolism: the effect of glucose on the excretion of phosphate in depancreatised dogs. Am J Physiol. 1926;76:525-31.

39. Xie W, Tran T, Finegood D, Van De W. Dietary P[i] deprivation in rats affects liver CAMP, glycogen, key steps of gluconeogenesis and glucose production. Biochem J. 2000;352:227-32.

40. Tanaka S, Yamamoto H, Nakahashi O, Kagawa T, Ishiguro M, Masuda M, et al. Dietary phosphate restriction induces hepatic lipid accumulation through dysregulation of cholesterol metabolism in mice. Nutr Rev. 2013;33:586-93.

41. Huang S, Czech MP. The GLUT4 glucose transporter. Cell Metab. 2007;5:237-52.

42. Becker TC, Noel RJ, Johnson JH, Lynch RM, Hirose H, Tokuyama Y, et al. Differential effects of overexpressed glucokianse and hexokianse I in isolated islets. J Biol Chem. 1996:271:390-4.

43. Sabbagh Y, Giral H, Caldas Y, Levi M, Schiavi SC. Intestinal phosphate transport. Adv Chronic Kidney Dis. 2011;18:85-90.

44. Elliott R, Morgan L, Tredger J, Deacon S, Wright J, Marks V. Glucagon-like peptide-1 [7-36] amide and glucose-dependent insulintropic polypeptide secretion in response to nutrient ingestion in man: acute post-prandial and 24-h secretion patterns. J Endocrinol. 1993;138:159-66.

45. Soltani N, Kumar M, Glinka Y, Prud'homme G, Wang Q. In vivo expression of GLP-1/lgG-Fc fusion protein enhances beta-cell mass and protects against streptozotocin-induced diabetes. Gene Ther. 2007;14:981-8.

46. Ye EQ, Chacko SA, Chou EL, Kugizaki M, Liu S. Greater whole-grain intake is associated with lower risk of type 2 diabetes, cardiovascular disease, and weight gain. J Nutr. 2012;142:1304-13.

47. Jenkins DJ, Kendall CW, Augustin LS, Martini MC, Axelsen M, Faulkner D, et al. Effect of wheat bran on glycemic control and risk factors for cardiovascular disease in type 2 diabetes. Diabetes Care. 2002;25:1522-8.

48. Kestenbaum B, Sampson JN, Rudser KD, Patterson DJ, Seliger SL, Young B, et al. Serum phosphate levels and mortality risk among people with chronic kidney disease. J Am Soc Nephrol. 2005;16:520-8.

49. Tonelli M, Sacks F, Pfeffer M, Gao Z, Curhan G, Cholesterol And Recurrent Events Trial Investigators. Relation between serum phosphate level and cardiovascular event rate in people with coronary disease. Circulation. 2005;112:2627-33.

50. Giachelli CM, Jono S, Shioi A, Nishizawa Y, Mori K, Morii H. Vascular calcification and inorganic phosphate. Am J Kidney Dis. 2001;38:S34-7.

51. Mathew S, Tustison KS, Sugatani T, Chaudhary LR, Rifas L, Hruska KA. The mechanism of phosphorus as a cardiovascular risk factor in CKD. J Am Soc Nephrol. 2008;19(6):1092-105. doi:10.1681/ASN.2007070760.

52. Di Marco GS, Hausberg M, Hillebrand U, Rustemeyer P, Wittkowski W, Lang $D$, et al. Increased inorganic phosphate induces human endothelial cell apoptosis in vitro. Am J Physiol Ren Physiol. 2008;294:F1381-7.

53. Lau WL, Pai A, Moe SM, Giachelli CM. Direct effects of phosphate on vascular cell function. Adv Chronic Kidney Dis. 2011;18:105-12.

54. Shuto E, Taketani Y, Tanaka R, Harada N, Isshiki M, Sato M, et al. Dietary phosphorus acutely impairs endothelial function. J Am Soc Nephrol. 2009;20:1504-12

55. Chang AR, Lazo M, Appel L, Gutiérrez OM, Grams ME. High dietary phosphorus intake is associated with all-cause mortality: results from NHANES III. Am J Clin Nutr. 2014;99:320-7.
56. Gutiérrez OM. The connection between dietary phosphorus, cardiovascular disease, and mortality: where we stand and what we need to know. Adv Nutr. 2013;6(4):723-9.

57. Kanauchi M. A new index of insulin sensitivity obtained from the oral glucose tolerance test applicable to advanced type 2 diabetes. Diabetes Care. 2002;25(10):1891-2.

\section{Submit your next manuscript to BioMed Central and take full advantage of:}

- Convenient online submission

- Thorough peer review

- No space constraints or color figure charges

- Immediate publication on acceptance

- Inclusion in PubMed, CAS, Scopus and Google Scholar

- Research which is freely available for redistribution 